\title{
OS COMITÊS ESTADUAIS DE SAÚDE E O ENFRENTAMENTO DO FENÔMENO DA JUDICIALIZAÇÃO DA SAÚDE
}

\section{COMMITTEES STATE HEALTH AND FACING THE PHENOMENON OF HEALTH JUDICIALIZATION}

\author{
${ }^{1}$ Homero Lamarão Neto \\ ${ }^{2}$ José Claudio Monteiro de Brito Filho
}

\section{RESUMO}

A procura por métodos consensuais de resolução de conflitos não é muito explorada nas demandas envolvendo o setor público. Os Comitês Estaduais de Saúde, criados por determinação do CNJ, com objetivo marcante de resolução consensual em questões de saúde pública, apresentam o diálogo e o debate acadêmico da medicina baseada em evidências como diretrizes para uma postura arrojada na garantia de direitos, inovando no comportamento do Poder Judiciário no enfrentamento do fenômeno da judicialização da saúde.

PALAVRAS CHAVE: Comitês; Diálogo; Judicialização; Saúde

\begin{abstract}
The search for consensus methods of conflict resolution is not much explored in claims involving the public sector. The State Health Committees, created by determining the CNJ, with remarkable goal of consensual resolution on public health issues, have dialogue and academic discussion of evidence-based medicine as guidelines for a bold stance on the rights assurance, innovating behavior the judiciary in coping with the legalization of health phenomenon.
\end{abstract}

KEYWORDS: Committees; Dialogue; Health; Judicialization

\footnotetext{
1 Doutorando em Direito - PPGD/UFPA, Universidade Federal do Pará, PA, (Brasil). E-mail: homerolamaraoneto@yahoo.com.br.

${ }^{2}$ Doutor em Direito - Pontifícia Universidade Católica de São Paulo - PUC, São Paulo, SP, (Brasil). Professor do Centro Universitário do Estado do Pará - PPGD/CESUPA e PPGD/UFPA - Universidade Federal do Pará, PA, (Brasil). E-mail: jclaudiobritofilho@gmail.com.
} 


\section{INTRODUÇÃO}

O fenômeno da judicialização da saúde tem registro relativamente recente no Brasil, não mais de duas décadas, se considerado o tempo de criação e implementação do Sistema Único de Saúde no país, a partir da Constituição Federal de 1988. Entre erros e acertos de uma política muito omissa e opaca de gestão da manutenção financeira do SUS, a ampliação das prestações dos direitos sociais fundamentais, sendo a saúde um de seus expoentes, caminhou ao lado da conscientização de direitos e, consequentemente, um nível mais alastrado de cobranças ao Estado.

Sem embargo de adentrar nos pontos primordiais que norteiam a discussão acadêmica acerca da avaliação, pelo Poder Judiciário, de questões envolvendo inadimplementos do poder público e, também, as políticas públicas que determinam as prestações sociais, é necessário avaliar o contexto em que o Poder Judiciário vem se posicionando em relação a esse quadro.

As audiências públicas realizadas pelo Supremo Tribunal Federal em abril e maio de 2009 bem refletem um cenário de mudança de paradigma, indicando que para a solução de determinados conflitos sociais seria imprescindível um debate mais amplo e participativo.

A criação do Fórum Nacional do Judiciário para monitoramento e resolução das demandas de assistência à saúde, através da Resolução CNJ 107/2010, plenamente demonstra essa dimensão, posicionando-se o Conselho Nacional de Justiça no sentido de que o Poder Judiciário deveria assumir um papel protagonista na solução eficiente e racional desse fenômeno, porém buscando no diálogo e no debate técnico o viés marcante para essa postura, propiciando a identificação do discurso como elemento central de solução alternativa ao litígio beligerante e massivo.

Assim foram pensados os Comitês Estaduais de Saúde. Aliando a técnica da medicina baseada em evidências com o diálogo estrutural, visando a satisfação do que a sociedade efetivamente almeja em termos práticos: o respeito às garantias constitucionais em torno da saúde pública.

Os Comitês Estaduais de Saúde simbolizam, portanto, uma nova forma de pensar a solução do litígio, preferencialmente na forma prévia através do diálogo, com o 
reconhecimento consensual de responsabilidades e gestão de encaminhamentos para que os magistrados possam utilizar material técnico, pautado na medicina baseada em evidências, como elementos robustos de responsabilização secundária, acaso o diálogo não venha a frutificar e o litígio seja instaurado.

Em razão do problema, e dos objetivos do estudo, a pesquisa desenvolvida se apresenta essencialmente analítica e descritiva, tomando-se por base as Resoluções do Conselho Nacional de Justiça e os Comitês Estaduais de Saúde já implementados nos estados do Pará e Rio Grande do Sul.

\section{CONSIDERAÇÕES INICIAIS SOBRE A JUDICIALIZAÇÃO DA SAÚDE}

Hodiernamente, a discussão acerca do direito à saúde gira em torno de um debate entre duas concepções destacadas. A primeira delas, de que se defronta com uma espécie de norma de cunho social, portanto, a ser deduzida a partir de políticas públicas concebidas e estruturadas pelo Estado, decorrentes de limitações orçamentárias preestabelecidas, onde se concentrariam as análises sobre a teoria da reserva do possível e das escolhas trágicas, dentre outras. Em contrapartida, há sustentação no sentido de que se trata de direito fundamental, portanto, direito público e subjetivo, sendo possível, no contexto da justiciabilidade dos direitos humanos, exigir uma prestação positiva e individual do Poder Público para garantia de sua efetividade.

No âmbito desse debate ${ }^{3}$, questiona-se acerca da possibilidade de se demandar os entes federativos vinculados ao Sistema Único de Saúde para disponibilização de medicamentos de alto custo, não necessariamente registrados na ANVISA. Em relação a esse último caso, perdura, também, o debate acerca da possibilidade de que tais medicamentos de

\footnotetext{
3 A matéria está em fase de julgamento no Supremo Tribunal Federal através dos Recursos Extraordinários 566.471/RN e 657.718/MG. Ambos os recursos tiveram repercussão geral reconhecida, influenciando, assim, todos os processos em andamento no país. Até o encerramento deste artigo, o Ministro relator Marco Aurélio já havia proferido seu voto, negando provimento a ambos os recursos, sob o entendimento de que os entes federativos podem ser obrigados a fornecer medicamentos de alto custo, ainda que não constantes nos protocolos do Sistema Único de Saúde, desde que: a) estejam registrados na ANVISA; b) houver demonstração de incapacidade financeira do paciente e de sua família para aquisição. O julgamento foi interrompido após pedido de vista do Ministro Luís Roberto Barroso, em 15/09/2016.
} 
alto custo sejam dispensados apenas aos mais necessitados ou a qualquer cidadão, em decorrência da universalidade norteadora do sistema de seguridade social ${ }^{4}$.

A compreensão de que o direito à saúde somente pode ser deduzido a partir das políticas públicas impediria a discussão de sua efetividade em ação individual, exceto para exigir o cumprimento de medida já prevista nas políticas estatais disponíveis. Assim, seria incabível discutir judicialmente o acesso a qualquer tratamento médico ou obtenção de medicamento não taxativamente garantido pelo Sistema Único de Saúde.

Ainda que os argumentos acerca do primeiro prisma não sejam centralizados em torno do conceito de norma programática, é importante frisar que muitos deles se encontram encadeados logicamente, porém despidos de uma necessária exposição prévia acerca de qual teoria da justiça legitimaria a adoção do raciocínio normativo apto a propiciar a conclusão no sentido de que o indivíduo não possui um direito prima facie a ser deduzido diretamente contra o Estado.

Com efeito, muitos desses argumentos prendem-se a uma concepção consequencialista de análise de resultados orçamentários, sempre partindo do pressuposto de que a escassez de recursos é um fator de limitação razoável para que não se possa exigir do Estado absolutamente nada além do que fora previsto em sua regulamentação de distribuição de serviços e medicamentos.

Prendem-se, ainda, a uma suposição de higidez do sistema orçamentário, corriqueiramente não abordando questões - que não são periféricas - como o desvio de verbas pela corrupção ou o contingenciamento deliberado por diretrizes políticas, nem sempre balizadas pelo interesse público primário - o qual deve nortear a conduta de qualquer agente público. Portanto, tornam-se lacônicos por não justificarem que, de forma recorrente, a maioria das ações judiciais em tramitação apenas e tão somente busca garantir o efetivo cumprimento de políticas públicas já existentes.

A partir das discussões travadas nas audiências públicas realizadas pelo Supremo Tribunal Federal (abril e maio/2009), com a finalidade de subsidiar o julgamento de recursos interpostos de decisões que reconheciam o direito a uma prestação positiva no campo da

\footnotetext{
${ }^{4}$ O Sistema Único de Saúde (SUS) é espécie do gênero sistema de seguridade social, como será melhor explicado nos itens seguintes.
} 
saúde, foi reconhecida no Agravo Regimental da Suspensão de Tutela Antecipada 175-CE a necessidade de distinguir duas situações.

A primeira delas, já assentada na doutrina e na jurisprudência, é no sentido de que, se a discussão judicial envolver acesso a tratamento ou obtenção de remédio garantido pelo Sistema Único de Saúde, não se cogitaria de invasão indevida do Poder Judiciário na esfera da política, eis que as políticas públicas estatais já garantem taxativamente o serviço.

A segunda, no sentido de que quando a prestação de saúde não está elencada dentre as disponíveis pelo SUS, quer por omissão legislativa, quer por mera deliberação administrativa de não fornecê-la, ou mesmo pela proibição da prestação, devendo ser destacado que a diretriz para tomada dessa decisão pode se circunscrever a um fator econômico e não necessariamente à franca possibilidade de se (re) analisar uma política de saúde mais adequada e eficaz, seria questionável e indevida a "invasão" do Poder Judiciário na "discricionariedade" do poder público.

O resultado desse cenário é a concentração de uma verdadeira avalanche de ações no Poder Judiciário, onde se questiona desde o descumprimento de protocolos da atenção básica, como exames e consultas, até as discussões mais contundentes, envolvendo dispensação de medicamentos de alto custo.

Obviamente, o incremento do quantitativo dessas ações proporcionou, em termos de gestão processual - sempre instruída sob as conotações de racionalidade, segurança e razoável duração do tempo do processo -, um olhar mais acurado do Conselho Nacional de Justiça, determinando-se a inclusão do julgamento preferencial de ações ditas coletivas ${ }^{5}$ nos ditames da meta n. 06/CNJ ${ }^{6}$, assim como um acompanhamento mais próximo desse cenário desde a criação do Fórum Nacional de Saúde, até o advento da Resolução CNJ 238/2016, que

\footnotetext{
${ }^{5}$ Embora não seja o foco deste artigo, reputamos conveniente salientar um equívoco mantido pelo CNJ na gestão da meta 06. As ações de saúde, quando ajuizadas, recebem códigos específicos para alimentação dos sistemas processuais. No Estado do Pará, por exemplo, que utiliza o sistema de gestão processual LIBRA, há única e exclusivamente 02 códigos de registro para as ações civis públicas. O comando 1690 é utilizado para as ações civis públicas referentes à área da infância (quer discutindo saúde quer outra matéria). O código 95 é destinado para todas as outras ações civis públicas. Esse equívoco proporciona um total descontrole na identificação (e geração dos relatórios de controle) de ações coletivas, pseudo-coletivas e individuais, pois há uma sensível discrepância entre o ajuizamento de uma ação civil pública para garantir um tratamento médico a fulano e o ajuizamento de uma ação civil pública para garantir que todos os usuários do SUS no Pará tenham acesso a um determinando protocolo médico, por exemplo. Até o encerramento desde artigo, nenhuma providência havia sido tomada no âmbito estadual.

${ }^{6}$ Julgar, até 31.12.2016, 60\% das ações coletivas ajuizadas até 31.12.2012.
} 
determinou a manutenção, pelos Tribunais de Justiça e Regionais Federais, de Comitês de Saúde, bem como a especialização de vara em comarcas com mais de uma vara de fazenda pública.

Antes de ingressarmos na análise desse quadro evolutivo para melhor compreender o intuito perseguido pelo Conselho Nacional de Justiça com a edição da referida resolução, abordaremos, de forma bem resumida, em razão dos limites do ensaio, a disposição da saúde pública na Carta Federal e os princípios do Sistema Único de Saúde que balizam uma premissa de igualdade na efetivação do direito fundamental à saúde.

\section{A SAÚdE PÚBLICA NA CONSTITUIÇÃO FEDERAL DE 1988}

A definição de saúde pela Organização Mundial de Saúde (OMS) é assentada na premissa de um estado de completo bem estar físico, mental e social, não se limitando à ausência de doença ou enfermidade. Não pretendemos, aqui, discutir as adequações ou inadequações do que poderia ser considerada a premissa de bem estar, tal qual apontam Segre e Ferraz (1997, p. 538), mas enaltecer que o legislador constituinte de 1988 obteve êxito em ampliar essa conceituação ao estipular o tratamento da saúde (nas facetas preventiva e curativa, através de políticas públicas sociais e econômicas) no texto da carta federal.

Importante frisar, de antemão, a nossa delimitação de abordagem no campo da saúde pública, ou seja, distinguindo-a da saúde suplementar ${ }^{7}$, eventualmente dispensada por planos de saúde, na medida em que o propósito do ensaio se limita ao objeto de atuação dos Comitês Estaduais de Saúde, como preconizados na Resolução CNJ 238/2016.

Instituída no bojo de um sistema de seguridade social, à saúde foi dispensada uma seção própria na Magna Carta, a seção II, no título da ordem social. Os sistemas de seguridade social são caracterizados, essencialmente, pela concepção de cidadania, onde todo e qualquer cidadão tem acesso às ações e serviços de saúde, independentemente de qualquer contribuição previdenciária, pagamento ou vinculação empregatícia.

\footnotetext{
7 No Brasil, especial atenção para a normatização estruturante da saúde suplementar através do Decreto 3.327/2000 (aprova o regulamento da Agência Nacional de Saúde Suplementar - ANS, e dá outras providências), Lei 9.656/98 (dispõe sobre os planos e seguros privados de assistência à saúde), Lei 9.961/2000 (cria a Agência Nacional de Saúde Suplementar e dá outras providências) e Lei 10.185/2000 (dispõe sobre a especialização das sociedades seguradoras em planos privados de assistência à saúde e dá outras providências).
} 
Em linhas gerais, conforme Paim (2009, p. 18-19), os sistemas de saúde seguem o tipo de proteção social adotado pelos países, destacando-se três tipos em todo o mundo: a seguridade social, o seguro social e a assistência. Ressalta Paim (idem, p. 12), que cada sociedade organizará seu sistema de saúde tendo como norte suas crenças e valores, sob a influência de determinantes sociais.

Os sistemas de saúde considerados universais são os destinados para toda a população, aí incluídos os modelos da seguridade social e do seguro social. Enquanto o primeiro, o da seguridade social, tem o acesso pautado na condição de cidadania, custeado pela sociedade em geral através de seu modelo tributário, no segundo, o do seguro social, somente o indivíduo que contribui com a previdência social terá acesso aos serviços de saúde, ainda assim, possibilitando aos que possuem condições financeiras, o acesso à assistência médica pela via de alguma contraprestação pecuniária.

Inglaterra, Brasil e Suécia podem ser destacados como países integrantes de um sistema de seguridade social. Portugal, Alemanha, Suíça e França se apresentam como integrantes do sistema de seguro social (PAIM, 2009).

O sistema de assistência, residual por excelência, proporciona atendimento (um pacote limitado de serviços) aos que comprovem a impossibilidade de efetuar a aquisição desses serviços diretamente no mercado. Os Estados Unidos da América se apresentam como país utilizador desse sistema. Aqui, o indivíduo que não pode adquirir um plano de saúde ou efetuar o pagamento diretamente a um profissional ou instituição, não tem a garantia de acesso aos serviços, exceto, como já frisado, se demonstrar sua condição de pobreza e, ainda assim, a serviços previamente identificados.

Paim (ibidem, p. 20) destaca que os Estados Unidos são o único país desenvolvido a permitir o atendimento à saúde da população sob a responsabilidade do mercado.

No Brasil, a partir da Constituição Federal de 1988, a saúde foi tratada, pela primeira vez, como um direito social fundamental, identificada como um direito de todos e dever do Estado. O artigo 196 da Carta Federal determina que esse direito será garantido mediante políticas públicas sociais e econômicas que visem à redução do risco de doença e de outros agravos e ao acesso universal e igualitário às ações e serviços para sua promoção, proteção e recuperação. 


\section{A CRIAÇÃO dO SISTEMA ÚNICO DE SAÚdE E A PREMISSA DE IGUALDADE NA EFETIVAÇÃO DO DIREITO FUNDAMENTAL À SAÚDE}

Conforme descrito acima, os sistemas de saúde podem se caracterizar, em linhas gerais e de forma exponencial, pelo regime da seguridade social, do seguro social e da assistência. A opção jurídica e política de escolha por cada sistema nas sociedades não ocorre exclusivamente a partir de uma questão econômica, em razão dos custos de implementação e de manutenção de cada um deles.

Em decorrência do caráter exponencial da saúde na vida do indivíduo (a saúde não deve ser enfatizada apenas pela ausência de doenças e enfermidades, mas por intermédio de todo o arcabouço de políticas públicas sociais e econômicas que influenciam diretamente no estado do indivíduo que lhe permite, a priori, a execução dos seus planos racionais de vida), ressalta a essa questão a forma como a sociedade decide sobre suas escolhas políticas e sociais, suas consequências e as responsabilidades advindas pelos efeitos dessas decisões numa sociedade de cooperação.

Aqui incide, precipuamente, a tônica de John Rawls (2009, p. 03-08) sobre a caracterização do objeto principal da justiça, que é a estrutura básica da sociedade. Essa estrutura básica, formada pelo conjunto das principais instituições e pelo modo como elas trabalham em conjunto para distribuir direitos e deveres fundamentais entre todos, determinando a divisão de vantagens que decorrem da cooperação social, não é totalmente aprofundada pelo autor em sua obra.

Apesar de ser inequívoca a menção de Rawls (2009, p. 08) sobre a constituição política e os arranjos econômicos e sociais mais importantes como elementos destacados das "principais instituições" que formam a estrutura básica da sociedade, há pontos não esmiuçados da teoria ralwsiana, segundo Rosas (2015, p. 24), que devem também incidir na leitura das "principais instituições" formadoras da estrutura básica da sociedade, como o conjunto das instituições que asseguram os direitos sociais (na cobertura dos riscos sociais, na educação e na saúde).

Nesse aspecto, conclui Rosas (2015, p. 25):

A estrutura básica da sociedade condiciona nossa vida desde que nascemos até que morremos. É a estrutura básica que determina, em função de regras institucionais, quem tem direito a quê desde o início da sua existência e ao longo da vida. 
Assim, a estrutura básica da sociedade, ao estabelecer o sistema único de saúde de acesso universal e igualitário deve levar em consideração não apenas questões no plano da homogeneidade dos indivíduos, criando um standard de ações e serviços hermeticamente estabelecidos através de suas políticas públicas, mas permitir ao indivíduo a discussão peculiar de determinadas patologias e circunstâncias, as quais, nem sempre, estão acobertadas pelo standard que se identificou, abstratamente, pelo prisma do acesso igualitário.

Se o sistema único de saúde (SUS), pautado pelo acesso universal e igualitário, por inúmeras razões, não pode estabelecer um padrão aberto e infinito de ações e serviços de saúde, as peculiaridades que cada indivíduo poderá apresentar ao longo de sua existência determinarão como, na sociedade de cooperação, onde se demonstra razoavelmente bem delineada a divisão de todos os direitos e deveres, assim como propiciada a divisão das vantagens decorrentes dessa cooperação, o Estado Democrático e Social de Direito deverá responder aos direitos fundamentais legitimadores, em última análise, do próprio funcionamento do Estado.

Especificamente no Brasil, apenas com a Constituição Federal de 1988 o direito à saúde foi tratado como direito social fundamental, pautado por um sistema único financiado com recursos específicos, porém conjuntos, de todos os entes federativos, tendo como diretrizes constitucionais a descentralização, o atendimento integral e a participação da comunidade.

Por descentralização, compreenda-se a adaptação do SUS à amplitude de nossa diversidade nacional, com nuances, muitas vezes, bem díspares entre as suas regiões, pontuando-se, ainda, as diferenças econômicas e sociais dos seus estados e municípios. Assim, as decisões do SUS são tomadas por comandos nos respectivos entes federativos através das secretarias de saúde, coordenando-se, no âmbito federal, pelo Ministério da Saúde.

Por atendimento integral, devemos atrelar à ideia de ações e serviços na promoção, na proteção e recuperação da saúde. A ideia é conjugar políticas preventivas e terapêuticas.

Por participação da comunidade, observe-se a necessidade de democratização dos serviços e decisões em relação à saúde. Paim (2009, p. 50) destaca que se trata de uma recomendação de organismos internacionais, como a Organização Mundial de Saúde (OMS), para o desenvolvimento de sistemas de saúde, principalmente depois da Conferência Internacional de Cuidados Primários de Saúde, realizada em Alma-Ata em 1978. Dessa 
forma, a comunidade teria condições de participar, identificando problemas, propondo soluções, fiscalizando ${ }^{8}$ e avaliando ações e serviços públicos de saúde.

A origem de nosso sistema único de saúde não ocorreu exclusivamente por debates constitucionais ocorridos na assembleia nacional constituinte, mas decorre de um amplo, lento e progressivo processo de reconhecimento desse sistema (SUS) sob um duplo aspecto: o combate à pobreza e a desigualdade social. Nas precisas palavras de Ocké-Reis (2012, p. 21), o SUS superaria o limite de cobertura anterior pautado pelo seguro social e o modelo privatista do regime militar no setor de saúde.

Pretendemos aqui esclarecer um ponto. Tudo que antecede à Carta Federal de 1988 em matéria de saúde pública, diz respeito à manutenção de um sistema de seguro social, no

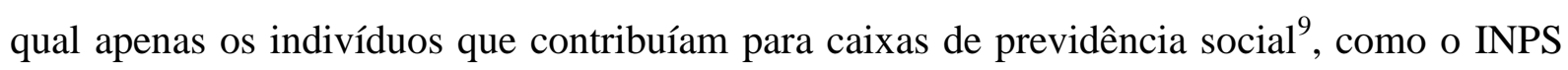
(então consolidado como órgão catalisador dessas caixas de previdência ${ }^{10}$ ), teriam acesso às ações e serviços de saúde. À população carente, apenas os serviços excepcionais de filantropia eram "garantidos".

Migramos, portanto, de uma tônica de sistema de ações e serviços de saúde para poucos até a contemplação da universalidade do SUS para qualquer cidadão, tendo ou não contribuído para esse sistema mediante contribuições à previdência social ou através de contraprestações diretas pelos serviços.

Acende, portanto, a ideia de igualdade, com a necessária leitura de equidade, no campo da saúde pública, a qual, contudo, ainda não atingiu o ponto desejável de maturação, pois inúmeras questões ainda não foram enfrentadas com a envergadura que o caso requer, como, por exemplo, a constituição de fontes específicas e estáveis de manutenção do SUS, a impossibilidade de contingenciamento de verbas do orçamento público afetadas para a implementação do sistema, a inclusão de norma específica que preveja o não atendimento das prescrições constitucionais de percentuais mínimos para as ações e serviços de saúde como atos de improbidade administrativa e a própria delimitação da equidade no acesso ao SUS.

\footnotetext{
${ }^{8}$ No âmbito da fiscalização, por participação da comunidade, merecem destaque as previsões da Lei 8.142/90 criando os "Conselhos de Saúde" compostos da seguinte forma: metade de representantes de usuários e metade de prestadores e trabalhadores do SUS. Esses conselhos atuam em caráter permanente, tanto no controle da execução das políticas de saúde (quer no aspecto econômico, quer no financeiro), como também na formulação de estratégias. Suas decisões se submetem à homologação do chefe do Poder Executivo. Devemos destacar que as funções fiscalizadoras e de proposição ocorrem sem prejuízo das funções do Poder Legislativo.

${ }^{9}$ Para os trabalhadores urbanos, com vínculo formal de trabalho, portanto.

${ }^{10}$ Segundo Paim (2009, p. 33), com exceção do IPASE (instituto de previdência e assistência de servidores do Estado), todos os institutos de previdência foram unificados em 1966 no Instituto Nacional de Previdência Social (INPS).
} 
Paim (2009, p. 40) salienta que todas as discussões e debates do denominado movimento pela democratização da saúde ou movimento sanitário foram imprescindíveis para a consolidação constitucional de um ideal de superação do paradigma de que o sistema de saúde seria destinado a poucos, contemplando todos os membros da sociedade, alcançando-se, assim, a previsão de acesso universal e igualitário às ações e serviços para sua promoção, proteção e recuperação.

Segundo o autor:

Ao apresentar o documento A questão democrática na área da saúde, no I Simpósio de Política Nacional de Saúde da Comissão de Saúde da Câmara dos Deputados, em 1979, o Cebes formulou, pela primeira vez, a proposta do SUS, justificando um conjunto de princípios e diretrizes para a sua criação. Desse modo, tanto a RSB ${ }^{11}$ quanto o SUS nasceram da sociedade, e não de governos ou partidos (PAIM, 2009, p. 40).

As Leis 8.080/90 e 8.142/90, delineadoras da implantação do SUS no Brasil, devem ser lidas, portanto, na contextualização da luta democrática para a criação de um sistema único de saúde de conotação universal e igualitária, na qual a previsão desse acesso igualitário não poderá jamais ser interpretada de forma hermética, desprezando-se o viés da equidade, na medida em que é justamente essa mitigação que evitaria, nas palavras de Paim (2009, p. 45), que atender igualmente os desiguais pudesse resultar na manutenção das desigualdades, impedindo que fosse atingida a igualdade material - aqui independentemente de classe social.

Nesse diapasão, não se pode deixar de frisar uma das conotações da criação do SUS, como outrora destacado: o combate à pobreza e a desigualdade social ${ }^{12}$. Não pretendemos,

\footnotetext{
${ }^{11}$ Paim (2009, p. 39) define o RSB como um movimento social, composto por segmentos populares, estudantes, pesquisadores e profissionais de saúde, que propôs a "Reforma Sanitária" e a implantação do SUS. Nele integravam instituições acadêmicas e sociedades científicas (como, por exemplo, a Sociedade Brasileira para o Progresso da Ciência - SBPC, o Centro Brasileiro de Estudos de Saúde - CEBES - e a Associação Brasileira de Pós-Graduação em Saúde Coletiva - Abrasco), entidades comunitárias, profissionais e sindicais. O movimento, criado na segunda metade da década de 1970, defendia a democratização da saúde e a reestruturação do sistema de serviços. Trata-se do movimento da RSB, conhecido também como movimento sanitário ou movimento pela democratização da saúde.

${ }^{12}$ No tocante à opção pelo sistema de seguridade social, Fluminhan $(2014$, p. 104) sustenta haver uma aproximação inequívoca da Constituição Federal com o Plano Beveridge, apresentado por William Beveridge ao Parlamento Britânico na década de 40 do século XX, evidenciando que a organização de um seguro social amplo e eficiente seria condição necessária para o progresso geral de um povo, cabendo ao Estado oferecer proteção social desde o nascimento até a morte do indivíduo. Dessa forma, objetivando a reforma e aperfeiçoamento do sistema de seguro social até então vigente, o Plano Beveridge sugeriu duas modificações substanciais: a) a extensão do seguro para abranger pessoas até então excluídas; b) ampliação da cobertura envolvendo a inclusão de riscos até então excluídos. Importante também destacar que o modelo de seguridade social adotado pelo legislador constituinte brasileiro, a partir de 1988, assenta-se sobre ações e serviços destinados a assegurar os direitos relativos à saúde, previdência e assistência social.
} 
nesse texto, desviar-nos da ideia de que as demandas judiciais de âmbito coletivo devem ser prestigiadas e enaltecidas, não apenas pela formal racionalização do sistema e da própria resposta do Estado às pretensões resistidas dos membros do grupo social.

Feitas essas ponderações, com o foco de esclarecer não apenas a disposição da saúde na Constituição, como também de expor o avanço social e a conquista do Sistema Único de Saúde através do diálogo no processo legislativo, gerando uma visão panorâmica de alguns dos elementos discutidos nas ações individuais de saúde, passaremos, então, à abordagem da Resolução CNJ 238/2016 e à consolidação da perspectiva de resolução consensual dos conflitos envolvendo a saúde pública.

\section{A RESOLUÇÃO CNJ N. 238/2016}

Em 06 de setembro de 2016, o Conselho Nacional de Justiça publicou a resolução n. 238, com dois intuitos: a) determinar a especialização de varas para processar e julgar ações que tenham por objeto o direito à saúde pública e orientem as varas competentes a priorizar o julgamento dos processos relativos à saúde suplementar; b) consolidar e aprimorar as diretrizes formuladas pela Resolução CNJ 107, de 06 de abril de 2010, que estabeleceu a necessidade de instituição de Comitês da Saúde Estaduais como instância adequada para encaminhar soluções para a melhor forma de prestação jurisdicional em área tão sensível quanto à da saúde.

Especificamente para o propósito deste trabalho, interessa o segundo objetivo, destacando-se, como já afirmado, que a referida resolução consolida e aprimora o que já havia sido indicado pela Resolução 107/2010, não apenas no tocante à criação dos Comitês Estaduais de Saúde, mas sobejamente o de aponta-los como instância de envergadura pertinente para o encaminhamento de soluções na resolução dos conflitos envolvendo a saúde pública, quer em conotação individual, quer coletivamente.

Em suma, o Conselho Nacional de Justiça aponta o diálogo como o caminho adequado para dirimir conflitos sociais, nesse aspecto trilhando a mesma direção do legislador ao instituir o novo código de processo civil, que enfaticamente almeja a resolução das lides pela conciliação e mediação. 
A Resolução CNJ 107/2010, instituidora do Fórum Nacional do Judiciário para monitoramento e resolução das demandas de assistência à saúde, decorrente das audiências públicas realizadas pelo Supremo Tribunal Federal em 2009, revela marcante preocupação com o crescimento dos litígios envolvendo demandas em saúde, motivo pelo qual se decidiu incumbir ao Fórum Nacional: a) o monitoramento das ações judiciais que envolvam prestações de assistência à saúde, como o fornecimento de medicamentos, produtos ou insumos em geral, tratamentos e disponibilização de leitos hospitalares; b) o monitoramento das ações judiciais relativas ao Sistema Único de Saúde; c) a proposição de medidas concretas e normativas voltadas à otimização de rotinas processuais, à organização e estruturação de unidades judiciárias especializadas; d) a proposição de medidas concretas e normativas voltadas à prevenção de conflitos judiciais e à definição de estratégias nas questões de direito sanitário; e) o estudo e a proposição de outras medidas consideradas pertinentes ao cumprimento do objetivo do Fórum Nacional.

O Fórum Nacional foi integrado por magistrados atuantes em unidades jurisdicionais, especializadas ou não, que tratavam de temas relacionados ao objeto de sua atuação, podendo contar com o auxílio de autoridades e especialistas com atuação nas áreas correlatas, especialmente do Conselho Nacional do Ministério Público, do Ministério Público Federal, dos Estados e do Distrito Federal, das Defensorias Públicas, da Ordem dos Advogados do Brasil, de universidades e outras instituições de pesquisa.

Como determinado pelo Fórum Nacional, foram instituídos comitês executivos, sob a coordenação de magistrados indicados pela Presidência e/ou pela Corregedoria Nacional de Justiça, para coordenar e executar as ações de natureza específica consideradas relevantes, a partir dos objetivos do artigo anterior, muito embora em algumas unidades da federação, como o Pará, em determinados momentos, outros órgãos tenham assumido a coordenação desses comitês (no caso atual, o Ministério Público Estadual).

Compostos de forma plural, com membros do Poder Judiciário Estadual e Federal, representantes do Ministério Público Estadual e Federal, membros da Defensoria Pública Estadual e da União, Secretarias Estaduais e Municipais de Saúde, Procuradorias Estaduais e Municipais, Advocacia Geral da União e representantes de planos de saúde, os comitês se reuniam com periodicidade fixa para deliberar não apenas sobre casos propostos envolvendo 
novos conflitos em matéria de saúde, como também atuando na composição de ações já ajuizadas.

O Comitê Executivo do Rio Grande do Sul ganhou destaque nacional, ao anunciar em 2015 que, nos últimos cinco anos, obteve êxito na redução do estoque de aproximadamente 30 mil ações judiciais relacionadas a pedidos de medicamentos e tratamentos de saúde. O comitê contava com representantes de 18 entidades, que pertencem tanto ao sistema de Justiça quanto aos sistemas de saúde público e privado, demonstrando a pluralidade no diálogo, elemento propulsor na redução dessas demandas.

De acordo com balanço realizado pelo $\mathrm{CNJ}$ em $2011^{13}$, tramitavam à época, no Judiciário brasileiro, 240.980 processos judiciais, sendo que, no Rio Grande do Sul, o TJRS concentrava quase metade de todas as demandas do país: 113.953 ações judiciais sobre saúde. A partir do trabalho realizado pelo Comitê Estadual da Saúde coordenado pelo tribunal, foi possível reduzir as demandas sobre assistência à saúde para aproximadamente 82 mil processos que tramitam atualmente no Estado.

Se os Comitês já eram mencionados na Resolução CNJ 107/2010, no que a Resolução CNJ 238/2016 inovou ao tratar de tema já abrangido em normativa anterior?

A nova Resolução não apenas corrobora o êxito de diretriz e de resultados dos Comitês, aperfeiçoando o diálogo como forma de resolução dos conflitos, como também contribuiu muito para a realização dos trabalhos desses Comitês e dos magistrados, de uma forma geral, registrando que o Comitê Estadual da Saúde terá entre as suas atribuições auxiliar os tribunais na criação de Núcleos de Apoio Técnico do Judiciário (NAT-JUS), constituído de profissionais da Saúde, para elaborar pareceres acerca da medicina baseada em evidências, observando-se na sua criação o disposto no parágrafo segundo do artigo 156 do Código de Processo Civil Brasileiro (recomendação de que o juiz seja assistido por perito quando a prova do fato depender de conhecimento técnico ou científico).

Os NAT's (Núcleos de Apoio Técnico do Judiciário) são extremamente importantes para consolidação de pareceres em matéria de saúde, proporcionando, através da medicina

\footnotetext{
${ }^{13}$ Disponível em http://www.cnj.jus.br/noticias/cnj/79186-tribunal-de-justica-consegue-reduzir-numero-deacoes-com-demandas-de-saude. Acesso em 24 de setembro de 2016.
} 
baseada em evidências, a compilação de soluções técnicas que subsidiam os magistrados na decisão mais acertada sobre a utilização de medicamentos e tratamentos discutidos em ações judiciais em curso ou casos propostos aos Comitês.

As discussões nos Comitês podem gerar a demonstração inequívoca de que um medicamento ou tratamento já é parte integrante dos protocolos do Sistema Único de Saúde, possibilitando, também, o direcionamento do adimplemento do caso ao ente federativo adequado (Estado e Município), funcionando como elemento modulador da regra de solidariedade do Sistema Único de Saúde.

Essa modulação é extremamente interessante e vantajosa, não apenas porque atribui a cada ente federativo o cumprimento rigoroso de suas obrigações constitucionais, como também porque promove a aferição de cumprimento do investimento percentual constitucionalmente assegurado em saúde pública pelos entes federativos. Esse exercício pode redundar, inclusive, na verificação, pelo Ministério Público, da prática de ato de improbidade administrativa pelos gestores que não aplicarem as receitas mínimas em saúde (conforme Lei Complementar 141/2012) e que estejam aderindo ao plano de gestão plena de saúde municipal com falhas (lacunas) reiteradas na prestação de serviços.

As deliberações dos comitês podem, ainda, proporcionar ampliação de protocolos para a comunidade, quando, por exemplo, os mesmos já estejam previstos em legislação do Sistema Único de Saúde, porém não implementados pelo ente, como, por exemplo, o Serviço de Atenção Domiciliar (SAD), garantido pela Portaria 963/2013, cujo funcionamento depende de adesão formal dos municípios ao programa do Ministério da Saúde.

Especificamente no âmbito do Estado do Pará, o Comitê Interinstitucional de Resolução Administrativa de Demandas de Saúde (CIRADS), formado ${ }^{14}$ e mantido sob a égide da Resolução CNJ 107/2010, possibilita que magistrados, promotores de justiça e defensores públicos façam consultas por meio eletrônico ao núcleo técnico do CIRADS, obtendo-se resposta em 72 horas acerca de medicamentos adequados à determinada patologia, tratamento e protocolo disponível na rede pública de saúde e inclinação vinculada do ente

14 Conforme Acordo de Cooperação Técnica 04/2014 e aditivos. Disponível em: <htpp://www.tjpa.jus.br//CMSPortal/VisualizarArquivo?idArquivo=13429>. Acesso em: 25 de Setembro de 2016. 
federativo responsável pela dispensação do medicamento ou protocolo no SUS, auxiliando, assim, a convicção cabal sobre insumos, protocolos e responsabilidades.

É oportuno ressaltar que, de acordo com o artigo $2^{\circ}$ da Resolução CNJ 238/2016, os tribunais deverão criar sítio eletrônico que permita o acesso ao banco de dados com pareceres, notas técnicas e julgados na área da saúde, para consulta pelos Magistrados e demais operadores do Direito, que será criado e mantido pelo Conselho Nacional de Justiça.

Esse banco de dados não interfere no já criado pela Comissão Nacional de Incorporação de Tecnologias no SUS (CONITEC), com funcionamento também pela via eletrônica, dirimindo dúvidas de magistrados de todo o Brasil sobre dispensação de medicamentos em casos concretos, protocolos e níveis de responsabilidade no atendimento, em tudo respeitada a regra constitucional de solidariedade dos entes.

Assim, as vantagens são inquestionáveis na efetivação desta modalidade consensual de resolução de conflitos, não apenas no prisma da satisfação breve de conflitos que envolvem a urgente satisfação do direito discutido, como também na redução de custos ao erário em relação aos processos e direcionamento para cumprimento adequado de políticas públicas pautadas na medicina baseada em evidências.

Conforme exposto por MANCUSO (2010), é necessária uma revisão conceitual, atualizada e contextualizada das noções de jurisdição e de acesso à justiça, na medida em que o aumento da oferta de prestação jurisdicional, além de não resolver o crescente aumento da demanda por "justiça", ainda retroalimentaria esse contexto, ao gerar uma expectativa social a que o Estado não consegue suprir ou, ao tentar fazê-lo, incidiria nos equívocos do gigantismo judiciário e do tratamento massivo dos processos.

A consolidação dos Comitês Estaduais de Saúde se apresenta como ratificação de trabalhos desempenhados com seriedade e eficiência, buscando, através de políticas públicas do Poder Judiciário, a solução racional de conflitos por intermédio do diálogo técnico. Se os Comitês estão bem distantes e aquém de apresentar uma solução definitiva para os problemas sociais enfrentados pela sociedade brasileira em relação às insuficiências da saúde pública, certamente estão muito além do cenário da observação passiva dos fenômenos sociais e do 
julgamento massivo e robotizado de duras e penosas questões que assolam brasileiros envolvendo a saúde pública.

\section{CONCLUSÃO}

A exploração de resultados pela via dialogada é extremamente vantajosa e interessante como demonstrado ao longo do texto. Embora a solução consensual não seja marcante nas demandas que envolvem o setor público, os Comitês Estaduais de Saúde se apresentam como via plural, técnica e arrojada para enfrentamento de um fenômeno a cada dia mais contundente no Poder Judiciário. Nesse cenário, o debate racional e técnico será um forte aliado para apresentação de resultados satisfatórios.

A franca possibilidade de congregar resultados de reconhecimento de competências não adimplidas, porém vinculantes, seu cumprimento voluntário por entes federativos e a possibilidade de se incrementar o controle sobre a gestão das receitas aplicadas na saúde pública não apenas criam expectativas positivas, como motivam o fortalecimento desses Comitês que deverão ser analisados minuciosamente para que seus resultados possam gerar criações similares, modificando-se o panorama de que o Poder Judiciário é, exclusivamente, a panaceia para todos os males.

As instituições representativas dos entes federativos que formarão os Comitês, como atualmente previstos na Resolução CNJ 238/2016, deverão, contudo, trabalhar conjuntamente com o Poder Judiciário para a concretização adequada das políticas públicas idealizadas e aprimoramento de seu controle interno na gestão dessas políticas, pois a mera participação dialogada sem revisão de comportamentos equivocados apenas transferiria o locus de administração da saúde pública, não se pretendendo que os Comitês funcionem como meras instâncias de correção de gestões impertinentes.

Sua função é para além da mera constatação de inadequações; um palco de projeções, avaliações palatáveis e resolução dialogada com responsabilidades, balizando-se sempre pelo debate aprofundado e pela medicina baseada em evidências. 


\section{REFERÊNCIAS}

ALMEIDA FILHO, Naomar de. O que é saúde? Rio de Janeiro: Editora FIOCRUZ, 2011.

CONSELHO NACIONAL DE JUSTIÇA. Tribunal de Justiça consegue reduzir número de ações com demandas de saúde. Disponível em <http://www.cnj.jus.br/noticias/cnj/79186tribunal-de-justica-consegue-reduzir-numero-de-acoes-com-demandas-de-saude>. Acesso em 24 de setembro de 2016.

CONSELHO NACIONAL DE JUSTIÇA. Resolução 107, de 06 de abril de 2010. Disponível em <http://www.cnj.jus.br/atos-normativos?documento=173>. Acesso em 24 de setembro de 2016.

CONSELHO NACIONAL DE JUSTIÇA. Resolução 238, de 06 de setembro de 2016. Disponível em <http://www.cnj.jus.br/busca-atos-adm?documento=3191> Acesso em 24 de setembro de 2016.

FLUMINHAM, Vinícius Pacheco. SUS x Tribunais: limites e possibilidades para uma intervenção judicial legítima. Curitiba: Juruá, 2014.

MANCUSO, Rodolfo de Camargo. A resolução dos conflitos e a função judicial no contemporâneo Estado de Direito. Interesse público, vol. 12, n. 60, mar./abr. 2010. Disponível em: http://dspace.almg.gov.br/xmlui/bitstream/item/3777/PDlexibepdf.pdf?sequence=1. Acesso em 7 dez. 2012.

OCKÉ-REIS, Carlos Octávio. SUS: o desafio de ser único. Rio de Janeiro: Editora FIOCRUZ, 2012.

PAIM, Jairnilson. O que é o SUS? Rio de Janeiro: Editora FIOCRUZ, 2009. 
RAWLS, John. Uma teoria da justiça. 3. ed. Trad. Jussara Simões, rev. Álvaro De Vita. São Paulo: Martins Fontes, 2008.

ROSAS, João Cardoso. Concepções da justiça. Lisboa: Edições 70, 2015.

SEGRE, Marco; FERRAZ, Flávio Carvalho. O conceito de saúde. Rev. Saúde Pública, São Paulo, v. 31, n. 5, p. 538-542, Oct. 1997. Disponível em $<$ http://www.scielo.br/scielo.php?script=sci_arttext\&pid=S0034-

$89101997000600016 \& \operatorname{lng}=\mathrm{en} \& \mathrm{nrm}=\mathrm{iso}>$. Acesso em 25 Set. 2016. http://dx.doi.org/10.1590/S0034-89101997000600016.

TRIBUnAl DE JUSTIÇA DO ESTADO DO PARÁ. Acordo de Cooperação Técnica 04/2014 e aditivos. Disponível em: <htpp://www.tjpa.jus.br//CMSPortal/VisualizarArquivo?idArquivo=13429>. Acesso em: 25 de Setembro de 2016.

VIEIRA-DA-SILVA, Ligia Maria. Avaliação de políticas e programas de saúde. Rio de Janeiro: Editora FIOCRUZ, 2014. 